Bulletin d'Histoire Contemporaine de l'Espagne

$51 \mid 2017$

Les forces politiques durant la Seconde République espagnole

\title{
Carmen Fernández Casanova (ed.), Estudios sobre Pablo Iglesias y su tiempo
}

\section{Francisco Sánchez Pérez}

\section{(2) OpenEdition \\ Journals}

Edición electrónica

URL: http://journals.openedition.org/bhce/803

DOI: $10.4000 /$ bhce.803

ISSN: 1968-3723

\section{Editor}

Presses Universitaires de Provence

Edición impresa

Fecha de publicación: 1 junio 2017

Paginación: 336-339

ISSN: 0987-4135

\section{Referencia electrónica}

Francisco Sánchez Pérez, « Carmen Fernández Casanova (ed.), Estudios sobre Pablo Iglesias y su tiempo », Bulletin d'Histoire Contemporaine de l'Espagne [En línea], 51 | 2017, Publicado el 09 octubre 2018, consultado el 24 septiembre 2020. URL : http://journals.openedition.org/bhce/803 ; DOI : https://doi.org/10.4000/bhce.803 
Esta obra recoge en gran medida el resultado de un congreso sobre la figura de Pablo Iglesias que se celebró en noviembre de 2010 en Ferrol, su ciudad natal, para conmemorar el centenario de la obtención de su acta como diputado en las Cortes, que marcó asimismo la entrada de la socialdemocracia en el parlamento español. Ya el congreso estuvo dirigido y coordinado en su día por Carmen Fernández Casanova, catedrática de la Universidad de A Coruña, que ahora lo hace con este volumen colectivo, al que aporta una breve introducción y su capítulo inicial. En él, aparte de ella, colaboran otros nueve especialistas que enfocan el problema central del pablismo desde diversos ángulos. En realidad va más allá de un libro sobre la figura del líder socialista o sobre su pensamiento político y actividades organizativas, aunque todo esto también se aborda, pues la idea del volumen es acercarse a varias de las circunstancias que convergieron e influyeron, o pudieron hacerlo, en su trayectoria vital en distintas etapas de ésta. Es decir, los vectores económicos, familiares, sociales, ideológicos y culturales, tocando casi todos los palos.

El trabajo se estructura en cuatro bloques temáticos. El primero dedicado a la experiencia ferrolana de la infancia del pequeño Paulino en sus diez primeros años de vida (1850-1860). De modo muy inteligente Fernández Casanova no sólo se centra en cómo era el Ferrol de la época, las oportunidades laborales que lo habían convertido en un centro de inmigración de cierta importancia local (el Arsenal), lo que pudo atraer a su padres, procedentes de otras partes de Galicia, o las malas condiciones del barrio de Esteiro en que creció, sino la relación de un Iglesias ya maduro y líder obrero con su ciudad natal, o por así decirlo la influencia de Ferrol en la memoria del propio Iglesias. Este estudio es acompañado por una minuciosa reconstruceión a cargo de Narciso de Gabriel sobre lo que podría definirse como las posibilidades educativas de la ciudad para un niño de familia obrera. Independientemente de las especulaciones acerca de dónde exactamente estudió Paulino, lo que el autor sostiene con acopio de datos es que Ferrol era un importante centro de alfabetización, es decir un polo de atracción educativo-cultural, y no solo económico-laboral, y de esto se benefició Iglesias, cuya desmedida afición por la lectura está más que atestiguada.

Un segundo bloque ilustra sobre la problemática de su infancia y adolescencia en Madrid, similar a la de muchos trabajadores urbanos del siglo XIX, en particular si fueron hospicianos, es decir si acabaron siendo, como Paulino, huérfanos (de padre, primero aquejado de una enfermedad mental y después fallecido) y obligados por las circunstancias a entrar en una institución de beneficencia para salvarlos de la muerte segura. De hecho sus dos hermanos murieron antes de llegar a la vida adulta. Su carácter de superviviente, su profundo desarraigo emocional separado obligadamente de su madre, su afición a la lectura de pliegos de cordel, la inexistente «adolescencia» de los hijos de los trabajadores y el temprano aprendizaje de los oficios en ese tipo de instituciones son descritos con mano maestra por el especialista Jorge Uría, junto a otros muchos detalles de la vida cotidiana de la época (desde el coste del transporte desde Galicia a Madrid a la expansión del sector juguetero). El panorama de la pobreza y lo que suponía el régimen del salario en el siglo XIX es completado por Ángeles Barrio, facilitando la comprensión de una de las ideas clave de Iglesias, arraigada en su propia experiencia societaria y en el debate teórico de la época en el movimiento obrero sobre el particular: que la dependencia del salario pagado por otros negaba la libertad de las personas que lo percibían. Y que semejante condición 
solo se aliviaría o desaparecería como resultado de la presión de los trabajadores sobre las autoridades. Como es sabido la mayoría de los asalariados y militantes del movimiento obrero eran varones, y esta triple condición la compartía Iglesias, y a sus ideas acerca de la emancipación de las mujeres, en particular en el mundo del trabajo de la época, pero también en el ámbito doméstico, está consagrado el capítulo de Mary Nash. Al centrarse esta aportación en el discurso de las organizaciones y publicaciones obreras sobre el particular y la influencia de las ideas de Iglesias sobre este discurso quizá habría resultado más lógico que este capítulo hubiese estado insertado en el siguiente bloque (sobre su liderazgo personal). En cualquier caso, lo que deja claro la autora es que las ideas de Iglesias, muy partidario de la igualdad de salarios entre hombres y mujeres, de la inclusión de estas últimas en las organizaciones obreras en pie de igualdad (y no expulsarlas de ellas como revienta-salarios) e incluso de la igualdad en el ámbito doméstico, eran muy minoritarias en las organizaciones filosocialistas y tenían que luchar en particular en los sindicatos con una visión radicalmente opuesta a la suya sobre el tema. Dato muy significativo porque muestra los límites de su liderazgo personal (y el de cualquier otro en organizaciones más o menos democráticas) y también los del discurso igualitario socialista. La concepción de que la mujer era la especialista en las tareas domésticas y debía ser protegida por ello en el trabajo asalariado para compensarla siguió siendo una idea tan arraigada que aún aparecía en los escritos de Margarita Nelken de entreguerras. Al mismo tiempo sin embargo el feminismo socialista también se había desarrollado lo suficiente para amparar ataques integrales contra la sociedad patriarcal a cargo de María Cambrils.

El tercer bloque temático se centra en el liderazgo personal de Iglesias sobre las organizaciones socialistas y ugetistas. Santiago Castillo desmiente de manera rotunda que las líneas programática y organizativa del PSOE y la UGT se debieran a sus opiniones personales que a su vez se impondrían al resto de la organización. Al desmenuzar las microetapas de su ascenso al liderazgo desde 1870 y hasta 1910 deja bastante claro que al menos hasta la etapa 1888-1898 no llegó a consolidarlo definitivamente, que su palanca de poder fundamental fue la dirección de El Socialista desde 1886, con lo que se convirtió en el auténtico asalariado liberado para profesionalizarse en la organización y convertirse en líder de opinión del partido. Y que como líder del PSOE y la UGT fue casi siempre el portavoz de las opiniones mayoritarias de la organización a la que representaba, incluida la negativa a la alianza con los republicanos de 1903. En su opinión el mito del «liderazgo impositivo» procedió de los ataques de los republicanos contra él a partir de los años noventa. En sus últimos años ejerció un liderazgo simbólico o de prestigio más que nada, siendo Besteiro y Caballero los que entraron al relevo. Sobre su beatificación postmortem abunda la colaboración de Pérez Ledesma, que compara su figura con la de August Bebel, el líder del SPD alemán muerto en 1913. Certera comparación en la medida que, pese a las marcadas influencias ideológicas francesas en el PSOE, a través de Guesde y Lafargue, tan reiteradas por la historiografía (y aquí también), el modelo organizativo español era calcado del de la socialdemocracia alemana, con la doble diferencia elemental, muy señalada en ésta y en otras contribuciones, de la unión del liderazgo del partido y del sindicato en particular sobre su persona y del escaso éxito de la fórmula a medio plazo en el caso español (lo que contrastaba mucho con el alemán a la altura de 1914). Aunque se echan en falta explicaciones más o menos plausibles del motivo o causa de ambas diferencias, que no parece que puedan exclusivamente circunscribirse a motivos endógenos de las propias organizaciones socialistas sin atender a las dinámicas del resto del movimiento obrero y las realidades sociales y económicas de la sociedad española de la época (frente 
a la alemana en particular). Sobre el papel de Iglesias en la configuración del modelo sindical y en particular huelguístico versa la colaboración de Michel Ralle, donde expresa muy agudamente los límites de la teoría marxista de la primacía de la acción política que debía encarnar el PSOE cuando «las posibilidades de actuar en el campo político eran casi inexistentes» (p. 219), y que finalmente se limitaba a la creación de una identidad social albergada por una sólida organización societaria, por medio de la cual se alcanzaría la soñada revolución social, motivo por el que se creó la UGT. También muestra la crisis de esta táctica de las huelgas localizadas y de objetivos alcanzables cuando se puso a prueba a partir de la coyuntura de fin de siglo con la emergencia de las huelgas generales como patrón de acción colectiva obrera preferente.

El cuarto bloque por último alberga dos contribuciones notoriamente dispares, algo por otra parte inevitable en este tipo de trabajos colectivos, sobre las tácticas socialistas hasta la muerte de Iglesias, es decir hasta los años veinte. Eduardo González Calleja defiende que los socialistas nunca dejaron de ser revolucionarios, pero que su concepción de la «revolución» era la de un cambio político y social profundo e irreversible y era lo suficientemente ambigua o si se prefiere flexible, siguiendo la tradición marxista no solo en España sino fuera de ella, para oscilar entre reforzar las organizaciones afines o abogar por reformas concretas presionando a las instituciones, incluidas campañas básicamente políticas como contra la guerra de Cuba o la de Marruecos, la coalición con los republicanos contra Maura (desde 1910) o las campañas pro-subsistencias durante la guerra mundial, y abogar por una huelga general prerrepublicana cuando les pareció necesario (1917 o 1930). Que todo eso, es decir dar pasos intermedios hasta llegar al poder político y a la sociedad sonada, lo consideraran «revolucionario» les insertaba en plena ortodoxia centrista dentro de la Internacional socialdemócrata antes y después de 1914.

Por el contrario Santos Juliá cree que el PSOE era un partido de retórica revolucionaria y de práctica reformista, con lo que se abona a la explicación de Bernstein (favorable a lo segundo) y a la de Lenin (desfavorable), que identificaban la revolución de forma reduccionista con la preparación de una insurrección violenta y armada para tomar el poder, a lo que desde luego no se dedicaba la mayoría de la socialdemocracia europea ni tampoco la española, al menos en los países donde había ciertas libertades civiles y derechos políticos, que había necesariamente que vulnerar si se pretendía tomar el poder de forma más o menos violenta. Cuando la derecha autoritaria tras 1918 empezó a reducir a los socialistas al silencio de forma progresiva en Europa sus percepciones sin embargo cambiarían un tanto. Los socialistas no parece que se vieran a sí mismos como ese tipo de «revolucionarios insurreceionales», pero sí creían que lo eran porque estaban consagrados a formar una contra-sociedad en expansión que funcionaba de una forma muy diferente respecto a la que les rodeaba ( $\mathrm{y}$ a su entender lo hacía de forma mucho más democrática), sociedad capitalista y desigual a la que se creían destinados a sustituir. En opinión de Juliá es síntoma de «dualidad» el tener un programa máximo (revolución social) y mínimo (reformas puntuales), como otros muchos partidos políticos por otra parte, tener un partido y a la vez un sindicato bastante afín (como harían otros muchos partidos en España, o lo intentarian, a partir de los años veinte o incluso antes) y gestionar a la vez sus dirigentes las acciones que el llama «económicas» (es decir, la acción directa ejercida por los propios trabajadores en el tajo) y las «políticas» (es decir, la acción política o indirecta, a través de los representantes electos). Pero además sostiene que esta actuación «dual» procede a su vez de una concepción maniquea/dual de la sociedad, es decir dividida entre obreros (los buenos) y burgueses (los malos), aunque no queda claro si en el 
maniqueísmo engloba al conjunto del movimiento obrero, a la socialdemocracia europea, o solamente a la española, que por otra parte afirma que está calcada en su diseño, que no en sus resultados, de la alemana, en lo que no podemos estar más de acuerdo. Tampoco parece que la semblanza de los socialistas como «antirrepublicanos», indiferentes a la forma de estado («accidentalistas») y «hasta antipolíticos» (p. 277) se compadezca mucho con las evidencias que él mismo muestra, entre otras la forma en cómo arriesgaron los herederos de Iglesias su propia organización en pro de una causa republicana y cien por cien política en 1917 y después en 1930-1931, lo que además les crearía serios problemas y divisiones internas por vincularse en exceso, en opinión de muchos militantes, a los «políticos» y a los «burgueses». Para no alargarnos demasiado, este mismo volumen muestra evidencias múltiples del deseo socialista de república, pero de república «social» («la social», según la inveterada fórmula decimonónica) o «socialista», no lógicamente por la «liberal»o «burguesa», que era considerada una mera transición, y en esto eran meridianamente ortodoxos en su época. Por poner un ejemplo bastante antiguo véanse las bases programáticas presentadas por Iglesias en el periódico recién fundado en 1886, donde junto al ataque a los partidos burgueses, preferentemente «los más avanzados» (los republicanos), sostiene por dos veces: «establecido el dilema de República o Monarquía, el Partido Obrero optará sin vacilar por la primera [...]; haciendo constar que entre las formas de gobierno republicana y monárquica, El Socialista prefiere siempre la primera» (p. 181, los subrayados son míos). No parece esto un manifiesto «accidentalista» o «indiferente» ante las formas de estado, se mire por donde se mire.

Por último, habría redondeado la gran utilidad del volumen la inclusión de una bibliografía común con las referencias usadas por los ponentes, habida cuenta que algunas son ineludibles, la lista no resulta demasiado larga en un volumen bastante manejable, y se repiten continuamente, desde los trabajos de Morato y el propio Santiago Castillo, a la última biografía de Serrallonga (2007) y los trabajos de Esperanza Piñeiro y Andrés Gómez Blanco sobre la presencia de Iglesias en Ferrol que aparecieron en ocasión del centenario de 2010. 